\title{
A Comprehensive Survey on Phasor Measurement Unit Applications in Distribution Systems
}

\author{
Mojgan Hojabri ${ }^{1, *}$, Ulrich Dersch ${ }^{2}$, Antonios Papaemmanouil ${ }^{1}$ and Peter Bosshart ${ }^{1}$ \\ 1 Competence Center of Electronics, Institute of Electrical Engineering, Lucerne University of Applied \\ Sciences and Arts, Horw 6048, Switzerland; antonios.papaemmanouil@hslu.ch (A.P.); \\ bosshart.peter@hispeed.ch (P.B.) \\ 2 Competence Center of Intelligent Sensors and Networks, Institute of Electrical Engineering, \\ Lucerne University of Applied Sciences and Arts, Horw 6048, Switzerland; ulrich.dersch@hslu.ch \\ * Correspondence: mojgan.hojabri@hslu.ch
}

Received: 26 October 2019; Accepted: 28 November 2019; Published: 29 November 2019

\begin{abstract}
Synchrophasor technology opens a new window for power system observability. Phasor measurement units (PMUs) are able to provide synchronized and accurate data such as frequency, voltage and current phasors, vibration, and temperature for power systems. Thus, the utilization of PMUs has become quite important in the fast monitoring, protection, and even the control of new and complicated distribution systems. However, data quality and communication are the main concerns for synchrophasor applications. This study presents a comprehensive survey on wide-area monitoring systems (WAMSs), PMUs, data quality, and communication requirements for the main applications of PMUs in a modern and smart distribution system with a variety of energy resources and loads. In addition, the main challenges for PMU applications as well as opportunities for the future use of this intelligent device in distribution systems will be presented in this paper.
\end{abstract}

Keywords: synchrophasor technology; phasor measurement unit (PMU); communication technologies; intelligent electronic device (IED); data quality; PMU applications; wide area monitoring system (WAMS); smart grids; distribution system

\section{Introduction}

Worldwide, increasing pressure is being placed on the electric power grids and in particular distribution systems due to the steadily increasing introduction of renewable energy resources (RESs). For this reason, the European Commission has a long-term plan to increase the use of RESs. Based on this plan, two-thirds of energy sources in Europe should come from RESs by 2050 [1]. Nevertheless, increasing RESs cause additional uncertainties in power systems [2-7]. Increasing RES penetration with their real-time dynamic characteristics combined with the decreasing ratio of stabilizing rotational mass leads to substantial challenges for the future of power grids to keep them robust enough for the requirements and expectations of consumers. One of the important challenges of using large-scale RESs is overcapacity generation [8]. In this case, electrical energy storage (EES) is helping to eliminate the uncertainties while providing more flexibility for the system and increasing the system performance [9]. As an example [10], if PV penetration increases to $100 \%$ in the UK, $57.1 \%$ of the loads should be fed via storage systems. Moreover, the average cost of the electricity generated is defined by the levelized cost of electricity (LCOE) factor. The authors in [9] show that EES is able to reduce the LCOE factor for systems including PV and EES. In addition, EES is useful for damping controls such as oscillation damping in distribution systems. Wide-area monitoring systems (WAMSs) enable the implementation of large-scale EES in distribution systems using real-time measurement provided by phasor measurement units (PMUs) [11]. 
Besides RESs and ESS, active loads such as demand responsive loads and electric vehicles (EVs) will also be increasing. All of these factors introduce new challenges in the operation, planning, protection, and control of distribution grids. Therefore, distribution systems must be able to accommodate new power flow patterns in more dynamic environments. This call for new solutions is to be covered by the introduction of smart grids. In a smart grid, power generation is not centralized but rather distributed. In addition, power flow is multi-directional. However, in conventional power grids, power generation is only centralized, and power flow is in one direction. In smart grids, consumption is integrated with the system operation. However, in a traditional power grid, operation planning is top-down. Moreover, unlike conventional power grids, which are operated based on historical experience and mostly offline data, in a smart grid system, operation is according to real-time data.

Traditionally, supervisory control and data acquisition (SCADA) systems have played a great role in power systems. They are efficient and reliable operation systems. Nowadays, the challenging issues for SCADA systems have changed due to new communication technologies and the necessity of fast access to power grid information [12]. In addition, traditional power grids have limited accessibility for new devices and technologies such as flexible AC transmission systems (FACTSs), high-voltage direct currents (HVDCs), intelligent electronic devices (IEDs), and PMUs. Power utilities also face many challenges, such as reducing emission, meeting the increasing electricity demand, using RESs, using aging assets optimally, and increasing the reliability of supply and energy efficiency.

A low sampling rate (2-4 samples/cycle) and a lack of time synchronization are important problems for SCADA systems. The synchrophasor technology seems to be a good solution. PMUs are electronic devices that work based on synchrophasor technology. PMUs are more accurate and faster (up to $50 / 60$ samples per cycle) compared to the SCADA system. In addition, they can be very useful in light of the dynamic behavior of a power system. Moreover, they can be implemented in most parts of a power system to achieve wide-area monitoring, protection, and control. However, due to the high cost of PMU installation, they are not widely used in distributions yet [13], as any new technology will add additional cost to system operators. Therefore, finding the minimum number of PMUs required and the optimal location for their installation is important for the cost-effective application of PMUs in power systems. For this reason, many studies [14-17] have been done according to graph theory to find the optimal placement of PMUs. In addition, methods have been introduced for optimal PMU placement based on their applications [18-20]. In this paper, the PMU concept as well as its evaluation and communication requirements are described in Section 2. Section 3 discusses the applications of PMU in power distribution systems. In Section 4, commercial PMU development and the capabilities thereof are presented. Finally, conclusions are drawn in Section 5.

\section{PMU}

IEEE 1344, IRIG-B, and IEEE C37.118 standards have described synchrophasor technology comprehensively $[12,21]$. A PMU is an electronic device that is able to estimate the synchrophasor, frequency, and the rate of change of frequency (ROCOF or $d f / d t$ ) of the acquired voltage and/or current waveforms, according to a united Coordinated Universal Time (UTC) reference [22]. Generally, PMUs are installed into an electrical substation and interfaced to an electrical grid via standard instrument transformers. A synchrophasor is the magnitude and angle of a cosine signal of voltage/current that is measured in an absolute point in time [23]. A sine wave and its phasor form are shown in Figure 1. 


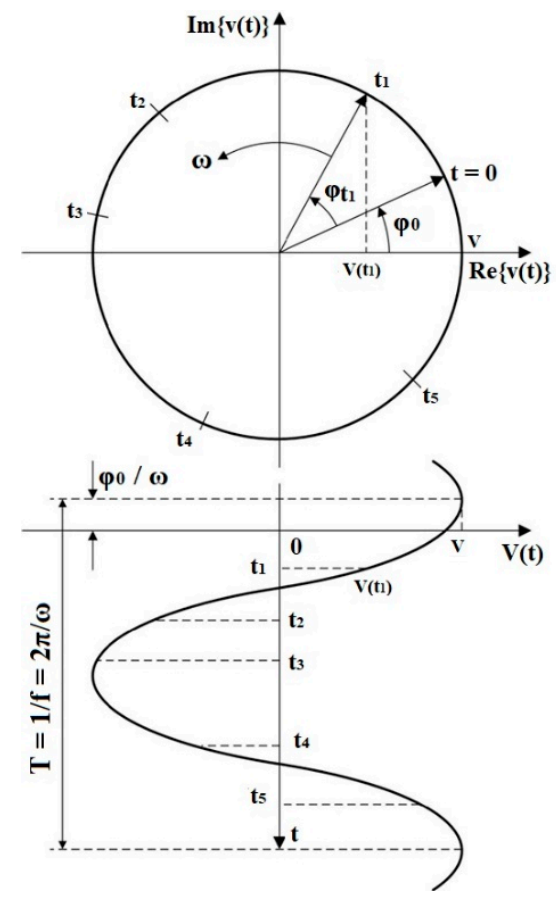

Figure 1. A sine wave vs. its phasor form [24].

The input data of a PMU are $\mathrm{V}(\mathrm{t})$ and $\mathrm{I}(\mathrm{t})$, which are measured directly from the current transformer (CT) and the potential transformer (PT). A fixed sampling rate is used with a synchronized global positioning system (GPS) clock [25], as shown in Figure 2. In power grids, similar to other commercial (non-military) uses, the civilian GPS signal is utilized. This signal has a $2.046 \mathrm{MHz}$ bandwidth and a $1575.42 \mathrm{MHz}$ center frequency, and it is available to all users. GPS has some advantages for power grids, such as its global coverage, free availability, and a $\mu$ s level of timing accuracy [26]. However, it is vulnerable to spoofing [27]. A phase-locked oscillator is also used for time tag generating (sending out with the phasors) within the second [28]. Time tags are added to the analog voltage and current signals, which pass through a filter and an analog-to-digital converter. Then, digital data is sent to a microprocessor to compute the voltage and current phasors, frequency, ROCOF, and binary information. These data are transferred within frames [29] to phase data concentrators (PDCs), which are normally located in primary substations to be used for archiving data for any offline assessment or online monitoring of system health.

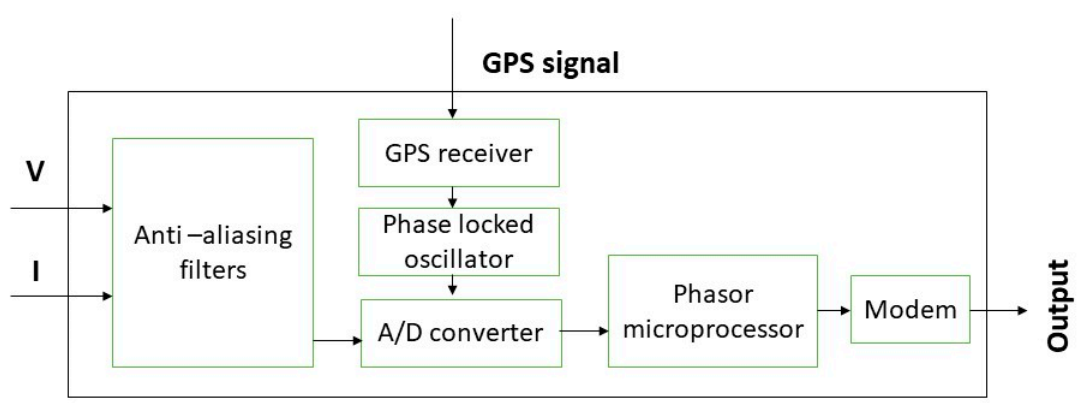

Figure 2. Phasor measurement units (PMU) block diagram.

The IEEE Std.C37.118.1-2011 [22] has determined two performance classes for PMU applications: a measurement $(\mathrm{M})$ class and a protection $(\mathrm{P})$ class. The $\mathrm{M}$ class has a lower response time but greater accuracy. It is important for applications with higher frequency requirements. The P class has a faster 
response time but less accuracy. It is suitable for real-time protection and control applications that require lower latency.

\subsection{PMU Performance Evaluation}

The main factors for PMU assessment are their availability, reliability, accuracy, latency, and message rate, which are described below:

- Availability means that data measured by the PMU can be sent to the PDC in a timely manner.

- Reliability is the strength and sufficient connectivity of the network for a prescribed performance level. A reliable and universal communication infrastructure is a crucial challenge in both the structure and the operation of WAMS communication systems.

- Accuracy is the difference between the measured value and the actual value. An accuracy index is using for the magnitude and angle, which is called the total vector error (TVE). The PMU performance standards refer to a $1 \%$ TVE [22]. However, this is changing based on PMU applications. TVE can be calculated by

$$
\begin{gathered}
\text { TVE } \triangleq \frac{|\widehat{X}-X|}{|X|} \\
=\frac{\left|\left(\widehat{X}_{r}+j \widehat{X}_{i}\right)-\left(X_{r}+j X_{i}\right)\right|}{\left|X_{r}+j X_{i}\right|} \\
=\sqrt{\frac{\left(\widehat{X}_{r}-X_{r}\right)^{2}+\left(\widehat{X}_{i}-X_{i}\right)^{2}}{X_{r}^{2}+X_{i}^{2}}}
\end{gathered}
$$

where $X$ is the true synchrophasor and $\widehat{X}$ is the synchrophasor estimated by the PMU. The subscripts $r$ and $i$ indicate the real and imaginary parts of the synchrophasor, respectively. In Figure 3, which represents a TVE, $V$ is the true phasor that should be measured, $V_{a}$ is the measured phasor with the magnitude error, and $V_{b}$ is the measured phasor with the phase and time synch error. Amplitude errors, phase errors, and synchronization accuracy are important factors influencing the TVE value.

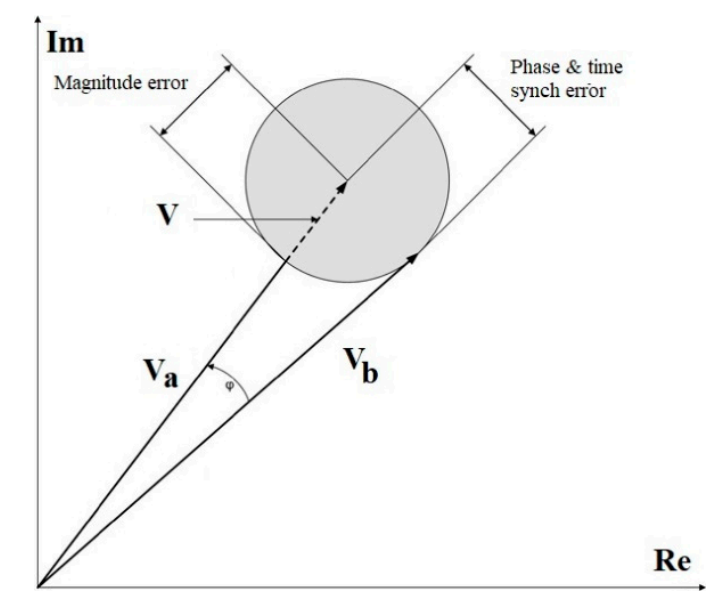

Figure 3. Total vector error (TVE) representation based on IEEE C37.118. 
In the case of a zero magnitude error and a maximum of $1 \%$ TVE, the maximum permissible phase angle error is $0.573^{\circ}$. At $50 \mathrm{~Hz}$, a full period is $360^{\circ}$ (Figure 1), which corresponds to $1 / 50$ of a second or $20 \mathrm{~ms}$. Therefore, the time accuracy requirement or timing error is calculated as

$$
\text { Time accuaracy requirement (timing error) }=\frac{0.573^{\circ} \times 20 \mathrm{~ms}}{360^{\circ}}=31.83 \mu \mathrm{s} .
$$

Measurement error directly affects the calculations. As an example, we measure here the transmission line impedance using a PMU as a model validation technique (Section 3.3.5). Thus, two PMUs are located at two points of a transmission line in Figure 4 to measure $50 \mathrm{~Hz}$ sinusoidal phase-to-phase voltages. PMUs estimate voltages as $V_{1}=11.55 \angle 4^{\circ} \mathrm{kV}$ and $V_{2}=11.25 \angle 3^{\circ} \mathrm{kV}$ and estimate the current phasor as $I_{1}=350.0 \angle 7^{\circ} \mathrm{A}$. Without measuring errors, the transmission line is equal to $1.02849 \angle 30.05^{\circ} \Omega$. However, by a $\pm 0.01^{\circ}$ angle error, the line impedance is in a range from $1.02225 \angle 29.51^{\circ} \Omega$ to $1.03482 \angle 30.05^{\circ} \Omega$. In addition, with a $\pm 0.05 \%$ magnitude error, line impedance is calculated with different values between $1.00101 \angle 31.08^{\circ} \Omega$ and $1.05632 \angle 29.08^{\circ} \Omega$.

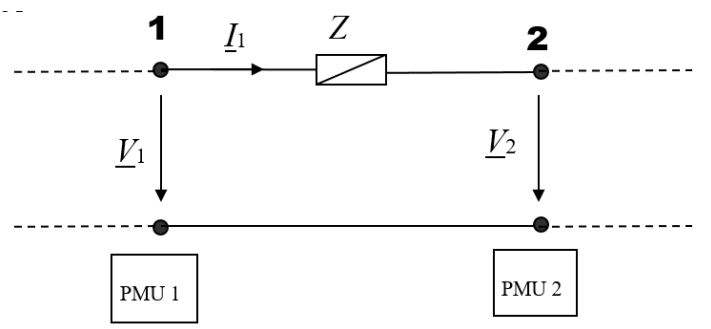

Figure 4. Transmission line.

- The latency or the time delay in a network is the time taken to transfer data from one point to another point. The WAMS latency stages are shown in Figure 5.

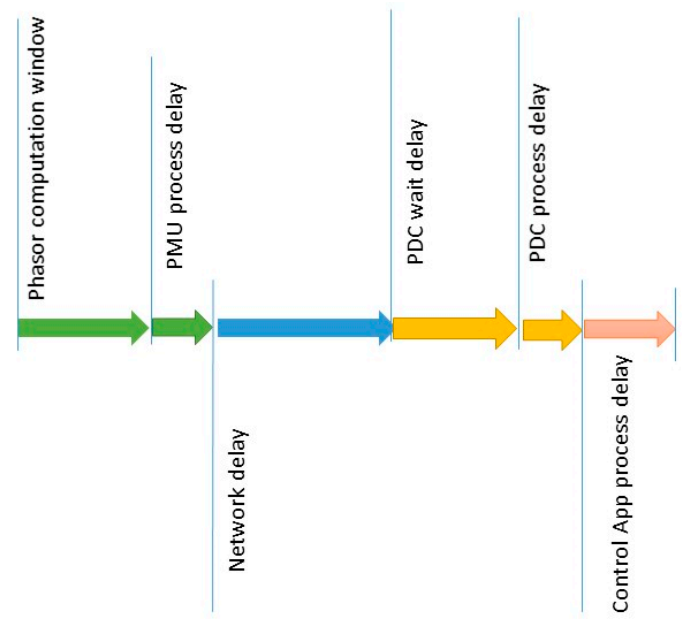

Figure 5. Wide-area monitoring systems (WAMS) latency stages [30].

- Message rate/resolution: A PMU takes many rapid physical measurements (samples) of voltage and/or current, computes phasor quantities from these samples, and then time-stamps and reports the phasor for each cycle or two cycles. Measured synchrophasors should be reported by a reporting rate, $F_{r}$, frequently [31]. The reporting rate is expressed in frames per second.

- Data loss: A PMU's data loss may occur due to GPS signal loss or communication network congestion. Generally, PDCs collect PMUs data based on the time stamp of the data stream. They also have a time-out function. Therefore, PMU data that does not arrive within a specified time will be dropped [32]. Based on the results of [33], most of the GPS loss events recover within a short period. 


\subsection{Communication}

SCADA systems use power line communication (PLC), overhead lines, coaxial cables, telephone lines, fiber optics, and radio frequencies through, for example, broadcasts, microwaves, and satellites [34] to transfer data. In a WAMS, two different communication categories are used. Wired communication technologies include PLC and fiber optics, and wireless communication technologies include Wi-Fi [35], WiMAX [36], long-term evolution (LTE), cellular communication (satellite), Bluetooth, ZigBee [37], microwaves, and radio [38-42]. These methods, with their advantages and disadvantages, are described in $[43,44]$ and are classified in Table 1 . Based on this table, fiber optics has a low latency and a high reliability. However, because of the higher capital expenses (CAPEX) and operational expenses (OPEX), PLC offers a cost-effective solution, as it does not require extra wires or infrastructure. Data can be sent on existing lines that transport electrical power. Two main PLC categories are narrowband (NB-PLC) [45,46] and broadband (BB-PLC) [47]. The frequency range for NB-PLC is up to $500 \mathrm{kHz}$, and that of BB-PLC is from 2 to $50 \mathrm{MHz}$. The data rate for NB-PLC is up to $200 \mathrm{kbps}$ and that for BB-PLC is over 1 Mbps. Nowadays, PLC is used for home automation, the control of city lightning, distributed energy resources (DERs), electric vehicles (EVs), automated metering infrastructure (AMI), remote metering, and demand responses. Moreover, PLC is used for the communication between substations and PMUs. Alongside its advantages, there are challenges for PLC, such as noise, attenuation, and signal distortion. Due to the low cost, infrastructure availability, and extensive coverage, PLC is still a possible option for PMU communications at medium voltage (MV) and low voltage (LV) distribution levels. In [48], a successful application of PLC for islanding in MV and LV distributions is reported. The authors in [49] introduce a new PLC technology called PLUS (Power Line data bUS). There are some advantages over the other PLC methods, such as a highly precise time synchronization solution, PLUS-TimeSync (in the range of $500 \mathrm{~ns}$ ), which is provided by the communication signal, and the communication functionality, which has been developed for MTC smart grid monitoring and automation (MTC-GMA) applications. Furthermore, it has the potential to provide robust and accurate wire-fault detection and load management algorithms.

The fifth generation of mobile networks (5G) will be another, and maybe the best, option for PMU communications in the future. $5 \mathrm{G}$ is around 100 times faster than existing mobile technology $(4 \mathrm{G})$ with a transfer rate of $20 \mathrm{Gbps}$ [50]. This new communication technology will support three important services. The first one is enhanced mobile broadband (eMBB), which provides connections with very high peak data rates and moderate rates of cell-edge users [51]. The second one is massive machine-type communications (mMTC). The mMTC will support a massive number of Internet of Things (IoT) devices with the possibility of making connections up to $10^{6}$ per square kilometer with a less than $1 \%$ packet loss rate [52]. The idea of 5G-based IoT is presented in [53] for DER communication with a control center. The last service that is supported by $5 \mathrm{G}$ is ultra-reliability low-latency communications (URLLC), which are very useful for the PMU communications in distribution systems, especially in the case of protection and control, which require more accuracy and very low latency (Section 3.1). 5G-URLLC was investigated in [52] for PMU communications for state estimation (SE) in a distribution system. The possibility of using $5 \mathrm{G}$ for the secondary load frequency control in a maritime microgrid (MMG) was explored in [54]. Based on their study, data measured by PMUs can transmit to a control center every $0.01 \mathrm{~s}$ via a $5 \mathrm{G}$ network. Nonetheless, this technology has not yet been not implemented in a real power system. If this technology is to be used in the future, its security must be guaranteed. 
Table 1. WAMS communication methods.

\begin{tabular}{|c|c|c|}
\hline $\begin{array}{l}\text { Communication } \\
\text { Method }\end{array}$ & Advantages & Disadvantages \\
\hline PLC & $\begin{array}{l}\text { Available infrastructure, extensive } \\
\text { coverage, high capacity, low cost } \\
\text { and latency }(150-350 \mathrm{~ms})\end{array}$ & $\begin{array}{l}\text { High noise sources over power lines due to } \\
\text { the noise generated by discharge across } \\
\text { insulator, corona and switching processes, } \\
\text { signal attenuation and distortion }\end{array}$ \\
\hline Fiber Optic & $\begin{array}{l}\text { High capacity, less repeaters, high } \\
\text { security, low latency }(100-150 \mathrm{~ms}) \\
\text { and low bit error less than } 10^{-15}\end{array}$ & $\begin{array}{l}\text { High initial cost and high service cost } \\
\text { prohibitive for a broad deployment in the } \\
\text { MV or LV grid }\end{array}$ \\
\hline Microwave & No cable required, medium cost & $\begin{array}{l}\text { Requires a license and line of sight for } \\
\text { operations, weather-dependent technology, } \\
\text { signal fading and multipath propagation }\end{array}$ \\
\hline $\begin{array}{l}\text { Wireless (Wi-Fi, } \\
\text { WiMAX, LTE) }\end{array}$ & Flexibility and low latency & $\begin{array}{l}\text { Capacity, serious security challenges, and } \\
\text { lower Quality of Service (QoS) }\end{array}$ \\
\hline Satellite & $\begin{array}{l}\text { Supports a wide geographical } \\
\text { coverage and high accuracy }\end{array}$ & $\begin{array}{l}\text { Weather conditions dependency, high initial } \\
\text { and operational cost, high round-trip delay } \\
(250 \mathrm{~ms}) \text {, and high latency } 1000-1400 \mathrm{~ms}\end{array}$ \\
\hline Radio & $\begin{array}{c}\text { Working based either on licensed } \\
\text { channels or over non-licensed } \\
\text { frequencies }\end{array}$ & Reliability for industrial use is questionable \\
\hline $5 \mathrm{G}$ & $\begin{array}{l}\text { Lowest latency less than } 1 \mathrm{~ms} \text { [52], } \\
\text { highest data rate (up to } 20 \mathrm{Gbps} \text { ), } \\
\text { high spectrum, network efficiency, } \\
\text { ultra-reliability }\end{array}$ & $\begin{array}{c}\text { The technology is new and it is under } \\
\text { process; high security assurance } \\
\text { required }[55,56]\end{array}$ \\
\hline
\end{tabular}

\section{PMU Applications in Distribution Systems}

The group of monitoring and assessment applications in power systems is called a WAMS. The SCADA system is not able to provide most of this information for power grids. As shown in Figure 6, the input data for both systems consist of an analog current and voltage, which comes directly from CT and PT. In SCADA systems, these data after processing will be sent to a remote terminal unit (RTU) as a digital RMS voltage and current. This microprocessor device interfaces devices in a real power system to a supervisory system, e.g., a distributed control system or a SCADA system, by transferring data to that system, and using messages sent from the supervisory system to control the connected devices. The communication between an RTU and a SCADA control system is based on IEC 61,850 and IEC 60870-5-104 standards.

WAMSs include PMUs, PDCs, super PDCs (regional PDCs), and communication between these parts. The output of a PMU consists of a voltage and a current in phasor form, frequency, and ROCOF. These data will be sent to a local PDC based on the IEEE C37.118.2 or IEC 61850-90-5 standards. Generally, PDCs are located at the primary substation (PS) where the collection of data from PMUs can be managed, and other PMUs within the same or neighboring PS can also communicate [57]. The important duties of a PDC include receiving data from PMUs, sending the synchronized data to super PDCs or other PDCs, monitoring the data, storing the data for event analysis, and checking for errors [58]. PDCs must make decisions with a very low latency of 10-100 ms (Figure 7). There are facilities for archiving data (offline and online applications). By using some IEDs, such as reclosers, switches, and capacitor banks, PDCs or super PDCs are able to protect and control the grid at the distribution or transmission level under their supervision so as to save the time and perform protection actions very quickly. Therefore, there is no need to send all the data directly to the SCADA system or the energy management system (EMS). It is sufficient to send an online alarm to the higher level; further information can be sent later on for further consideration. The authors in [59] present another idea for the future of WAMSs. In this scenario, the IEEE C37.118.2 protocol is replaced by the IEC61850-90-5 
protocol for fast communication between all parts of a WAMS. Moreover, the IEC 61,850 protocol can be applied for high-speed communication between relays.

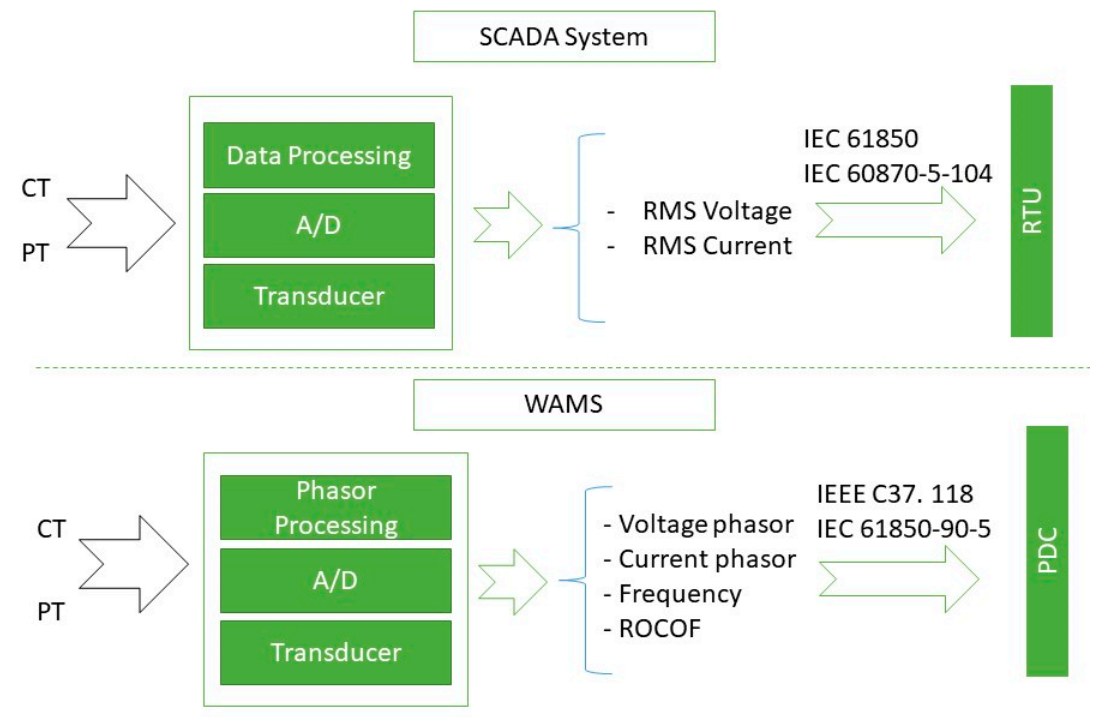

Figure 6. Supervisory control and data acquisition (SCADA) vs. WAMS.

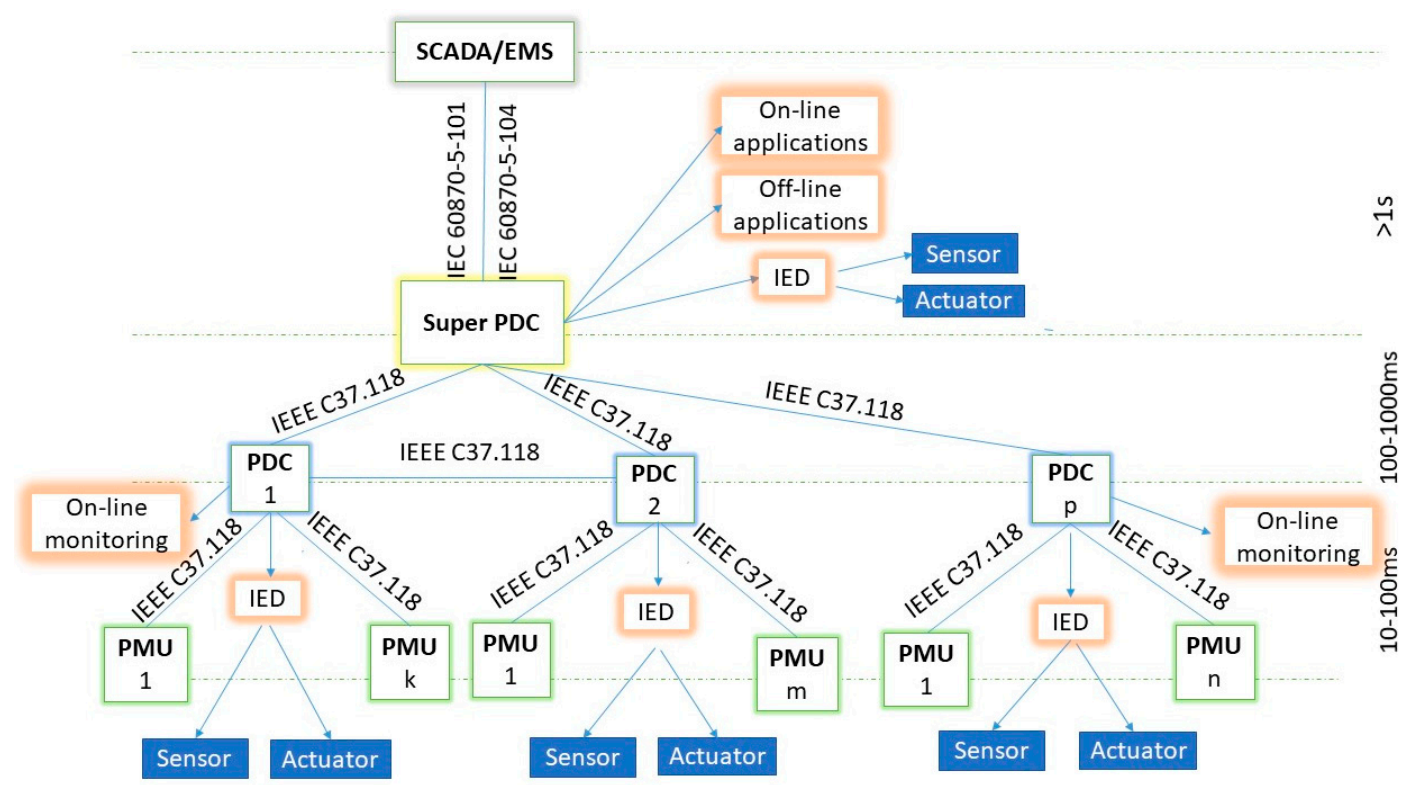

Figure 7. WAMS architecture.

In a transmission system, PMUs are utilized in order to achieve a higher accuracy of voltage magnitude and angle in order to be used in wide-area situational awareness and monitoring such as wide-area frequency monitoring, voltage stability monitoring, and oscillation monitoring and detection. Besides that, PMUs are used for SE, fault detection, and fault location. In distribution systems, because of the increasing number of active loads and RESs, PMU applications are more useful. However, the characteristics of distribution systems are less balanced, with more volatile currents and voltages. In addition, because of the small angle differences between bus voltage and line current, the transferred phasors values must be more accurate compared to the transmission system [60].

Due to the complex nature of a power system, it is very important to monitor and protect all parts of the system continuously. The main requirements to achieve the successful analysis, operation, 
and control of distribution networks in real time are related to the topology and state of the system. Topology is defined by the interconnection between power system components and is almost constant. However, the state (the voltage and angle for all buses) changes all the time [61]. Considering all PMU applications in the two main categories (steady state and dynamic), in steady-state applications, a medium bandwidth with continuous data transfer is required. However, the sample rate can be as low as one or two samples per cycle, with a lower data transfer. For dynamic applications, a high bandwidth and high-speed communication are necessary, even though the expected sample requirements for dynamic applications changes between 2 and 512, depending on the application [62]. Based on the North American Synchrophasor Initiative (NASPI) report in [33], PMU applications in a power system can be classified in four main classes: Automation (Class A), Reliability (Class B), Planning (Class C), and Operation (Class D), as shown in Table 2, with classifications of 4 (critical), 3 (important), 2 (somewhat important), and 1 (less important).

Table 2. Classification of PMU applications in power systems.

\begin{tabular}{cccccc}
\hline Class & Application & Accuracy & Availability/Reliability & Low Latency & Message Rate \\
\hline A & Automation & 4 & 4 & 4 & 4 \\
B & Reliability & 2 & 2 & 3 & 2 \\
C & Planning & 4 & 3 & 1 & 4 \\
D & Operation & 1 & 1 & 2 & 2 \\
\hline
\end{tabular}

\subsection{Power System Automation (Class A)}

This category is related to the automated protection and control applications of PMUs in distribution systems, which are advanced applications. The aim of these applications is to improve the reliability and security, automated remedial action schemes, and asset utilization. Some of these applications with their data quality and communication requirements are listed in Table 3. In this table, the accuracy and data rates are defined based on a $50 \mathrm{~Hz}$ frequency system and can be easily changed to a $60 \mathrm{~Hz}$ system. Based on Table 3, this group of applications requires high availability and accuracy. In addition, they need a high message rate and a low latency $(\leq 100 \mathrm{~ms})$ to communicate with switches, reclosers, and DER units for control reasons [63]. However, in the case of teleprotection, communication should be faster ( $\leq 10 \mathrm{~ms}$ latency), and reliability must be very high [63].

\subsubsection{Microgrid Operation}

Microgrid operation refers to islanding, load and generation balance, and resynchronization. Islanding might happen after a disturbance in a power system. In this situation, the faulty part should be isolated by the main circuit breaker. Islanding occurs when the connection between the main utility and the supplying power is disconnected while the microgrid continues to supply power e.g., from photovoltaic farms into the distribution networks. There are two types of islanding. Intentional islanding is used for electric grid maintenance. Unintentional islanding occurs in fault conditions and equipment failures [64]. Active and passive methods are used for islanding detection [65]. PMUs are very helpful for islanding detection and fast distributed generator (DG) disconnection from the grid (within only 2 s) based on the IEEE Standard 157-2008 [66]. In this case, PMUs should send voltage magnitudes and phase angles within $50 \mathrm{~ms}$ [67]. Some research in this area has been done [68-70]. Reconnecting an islanded part of the microgrid is called resynchronization. Another PMU application in microgrid operations is resynchronization. PMUs are also helpful for balancing the power generation and load in microgrids during islanding. For any PMU applications in microgrid operation including islanding, load and generation balance, and resynchronization, voltage phase angles are essential. Microgrid operations are also insensitive to magnitude error (Table 3). In addition, a $0.01^{\circ}$ phase angle is required [71]. 
Table 3. Expected data requirements for power system automation.

\begin{tabular}{|c|c|c|c|c|c|}
\hline \multicolumn{2}{|c|}{ Application } & Accuracy $(\mu s)$ & Continuity & Latency (ms) & Message Rate (rep/sec) \\
\hline \multirow{3}{*}{$\begin{array}{l}\text { Microgrid } \\
\text { Operation }\end{array}$} & Islanding & \multirow{3}{*}{$<0.0174$} & \multirow{3}{*}{$\begin{array}{l}\text { Continuous } \\
\text { monitoring }\end{array}$} & \multirow{3}{*}{$\begin{array}{l}\text { Sub-second } \\
\text { latency critical } \\
\text { if informing } \\
\text { protection (50) }\end{array}$} & 50 \\
\hline & $\begin{array}{l}\text { Load and generation } \\
\text { balance/frequency } \\
\text { stability }\end{array}$ & & & & \\
\hline & Resynchronization & & & & \\
\hline \multirow{5}{*}{$\begin{array}{l}\text { Fault } \\
\text { Detection } \\
\text { and } \\
\text { Location }\end{array}$} & $\begin{array}{l}\text { Out of step } \\
\text { protection }\end{array}$ & 31.81 & $\begin{array}{l}\text { Continuous } \\
\text { monitoring }\end{array}$ & 10 & 50 \\
\hline & $\begin{array}{c}\text { Low- and } \\
\text { high-impedance } \\
\text { faults }\end{array}$ & \multirow[t]{3}{*}{15.915} & \multirow[t]{3}{*}{$\begin{array}{l}\text { Continuous } \\
\text { monitoring }\end{array}$} & \multirow[t]{3}{*}{20} & 50-100 \\
\hline & $\begin{array}{l}\text { Equipment health } \\
\text { diagnostics }\end{array}$ & & & & \\
\hline & Fault detection & & & & \\
\hline & Fault location & 100 & $\begin{array}{l}\text { Continuous } \\
\text { monitoring }\end{array}$ & 1000 & 50 \\
\hline \multirow{3}{*}{ Control } & $\begin{array}{l}\text { Short-term stability } \\
\text { control }\end{array}$ & 31.81 & - & 16 & 50 \\
\hline & Phasor-based control & $\begin{array}{l}\text { Accuracy is } \\
\text { critical }\end{array}$ & $\begin{array}{l}\text { Continuous } \\
\text { monitoring }\end{array}$ & $\begin{array}{l}\text { Latency is } \\
\text { critical }\end{array}$ & 50 \\
\hline & $\begin{array}{c}\text { power system } \\
\text { controlling with } \\
\text { FACTS devices/smart } \\
\text { switchable networks }\end{array}$ & 31.81 & - & 16 & 50 \\
\hline
\end{tabular}

\subsubsection{Fault Detection and Location}

Most faults in a power system occur at the distribution level. Traditionally, utility employees or crew travel along the feeder to find the fault location (FL) based on the operation of the protection device or the reported customer outage. Using a PMU reduces the outage duration and cost. Moreover, the accuracy of an FL can be improved by applying synchronized measurements of currents or voltages. Until now, many faults have been detected by PMUs in distribution systems [72-78]. However, some FL methods use only current or voltage phasors $[79,80]$. For maximum accuracy, both current and voltage phasors must be used [71]. An accurate FL requires a synchronized phasor measurement with a time resolution of at least $1 / 50$ of a second and a corresponding time error of $100 \mathrm{us}$ [47].

\subsubsection{FACTS Devices}

Distributed FACTS (D-FACTS) devices are commonly used for voltage profile improvement, power loss reduction, and load balancing in distribution systems [81,82]. D-FACTS devices by the injection of active and reactive power into the power grid can compensate the sensitive loads [83]. PMUs can be connected to FACTS devices or other switching protection devices to control the distribution system very quickly. For this reason, voltage and current phasors with an expected accuracy of $0.01 \mathrm{pu}$ in magnitude and 0.5 degrees are needed, as shown in Table 3 [31].

\subsection{Power System Reliability/Coordination (Class B)}

Based on the information in Table 2 for this class of PMU applications, latency is important, and other factors (accuracy, availability, and message rate) are somewhat important as well. These types of PMU applications can be divided into topology and disturbance detection and for situational awareness. The long-term goals for these PMU applications are improving reliability, situational awareness, etc. 
Situational Awareness

Traditionally, distribution systems face many challenges in achieving situational awareness because of the lower voltage and the larger number and variety of utility and customers. Moreover, the lack of high-resolution measurements (every $15 \mathrm{~min}$ ) and accurate and up-to-date models of distribution circuits are other factors [84].

In smart grids, high-resolution voltage and current phasors measured by PMUs can be used for accurate situational awareness [85-87]. The data requirements for some situational awareness are listed in Table 4.

Table 4. Expected data requirements for power system reliability.

\begin{tabular}{ccccc}
\hline & Application & Accuracy $(\mu \boldsymbol{s})$ & Latency $(\boldsymbol{m s})$ & Message Rate $(\mathrm{rep} / \mathrm{sec})$ \\
\hline $\begin{array}{c}\text { Situational } \\
\text { Awareness }\end{array}$ & $\begin{array}{c}\text { Awareness of real-time load } \\
\text { Situational awareness } \\
\text { dashboard }\end{array}$ & 15.915 & 1000 & 50 \\
& $\begin{array}{c}\text { Anomaly characterization } \\
\text { and alarming }\end{array}$ & 31.81 & 100 & 25 \\
\hline
\end{tabular}

\subsection{Power System Planning (Class C)}

Power system analysis and assessment applications are in this category. Accuracy, compared to latency, is more important for these applications. The long-term goals for power system planning applications are a better system understanding and improved system modeling.

\subsubsection{State Estimation (SE)}

SE is used to define the present operating state of a power system. Traditionally, a set of analog measurement data, such as voltage, current, and active and reactive power, is used to estimate unknown variables. Without PMUs, all of these measurements and calculations are done by RTUs under a SCADA system, and it takes around 2-5s. However, with PMUs, it is possible to observe state variables directly. Therefore, the capturing time can be reduced to 30-40 ms [60]. Moreover, traditional data measurement is asynchronous. Therefore, SE is a static SE (SSE) $[88,89]$. However, with synchrophasor technology, dynamic SE (DSE) [90-94] is used to define the steady-state voltage magnitude and phase angle at each node of the power system. An SE-based PMU is used in both the transmission and the distribution network. However, such use is more difficult in distribution systems because of the complication of distribution system modeling, and because of the phase imbalances, there is a small $\mathrm{X} / \mathrm{R}$ ratio, a large number of connections, and less redundancy (from Kirchhoff's laws) [95]. SE is also sensitive to the placement and number of sensors. Moreover, the network model and load data are important for SE. SE requires an absolute accuracy of about $0.0001 \mathrm{pu}$ [73], and requires correction for transducer errors (Table 5). The corresponding time error requirement is 0.3181 us [73], and the communication requirement delay is expected to be $100 \mathrm{~ms}$ [69].

\subsubsection{Voltage Stability}

Monitoring the dynamic behavior of voltages will help keep voltages within their limits. In addition, reactive power, peak power, and power loss will be minimized. Therefore, many studies have been done on PMU applications in terms of voltage stability and control [96-100]. Voltage stability monitoring and assessment requires a transfer time of $500 \mathrm{~ms}$ [31].

\subsubsection{Power Quality Analysis}

Electrical power quality, or simply power quality, means not only quality but also reliability. Power supply is without variation or distortion in frequency and waveforms (voltage and current). The most common power quality issues in distribution systems are the following: 
- voltage interruption;

- voltage disturbances, such as voltage sag/swell, transient, impulse, etc;

- waveform quality problems, such as magnitude, imbalance, harmonics, flicker, etc.

A PMU helps identify changes in voltage, current, and frequency through the real-time monitoring of the system. Therefore, PMUs can be very useful for analyzing power quality issues. For power quality analysis, the expected TVE is $0.5-1 \%$ [73].

\subsubsection{DG Characterization}

DGs offer many advantages, including the generation of power close to the point of consumption. However, grid-connected distributed generators providing reverse power flow will cause changes to the power grid [101]:

- Increases in short circuit levels;

- Changes to voltage profiles;

- Congestions in system branches;

- Power quality and reliability issues; and

- Malfunctioning power grid protections.

DG characterization is the qualification and quantification of the behavior of grid-connected inverters to increase system stability. Online monitoring of the active and reactive power of DGs enables responses to abnormal situations. PMUs can be used for the observation of DG behavior in distribution systems. Synchrophasor technology is helpful for the following:

- Reversed power flow detection;

- Feeder voltage coordination based on DG behavior; and

- Disaggregate net metered DG from load.

For these cases, voltages and current phasors require a 0.5\% TVE, which is equal to a $15.915 \mathrm{us}$ corresponding time error in a $50 \mathrm{~Hz}$ system. There is no particular requirement for continuity or latency [102]. In addition, the expected sample rate is 50 and 60 reports per second for $50 \mathrm{~Hz}$ and $60 \mathrm{~Hz}$ systems, respectively [101].

\subsubsection{Model Validation}

Model validation in a power system is the validation of line segment impedances, transformers, load models, generator models, etc. A complete model should provide information regarding the impedance and connectivity of each electrical component in the power grid. Regular system model validation is necessary for a secure and reliable power system [103]. Accurate voltage and current phasors can be helpful for computing the impedances of line segments or other components. Therefore, PMUs enable a dynamic model validation. Data quality, specifically accuracy, is important for this application. For line segment impedance validation, the absolute accuracy of all phasors is a limiting factor, which should be around $0.0001 \mathrm{pu}$ for shorter segments. The expected time error requirement is 0.3181 us [73]. For the model validation of other components, voltage and current phasors with an expected $0.5 \%$ TVE are required. No continuity or latency is particularly necessary (Table 5). An example of model validation is explained in Section 2.1. 
Table 5. Expected data requirements for power system planning.

\begin{tabular}{|c|c|c|c|c|}
\hline & Application & Accuracy $(\mu s)$ & Latency $(m s)$ & Message Rate (rep/sec) \\
\hline \multirow{4}{*}{$\begin{array}{c}\text { Model } \\
\text { validation }\end{array}$} & Line segment impedances & 0.3181 & \multirow{4}{*}{$\begin{array}{l}\text { No particular } \\
\text { need for } \\
\text { latency }\end{array}$} & \multirow{4}{*}{$50 / 60$} \\
\hline & $\begin{array}{c}\text { Transformer and other } \\
\text { device models }\end{array}$ & \multirow{3}{*}{15.915} & & \\
\hline & Load models & & & \\
\hline & Generator models & & & \\
\hline \multirow{5}{*}{$\begin{array}{l}\text { Power quality } \\
\text { analysis }\end{array}$} & System oscillation detection & \multirow[t]{3}{*}{15.915} & $\begin{array}{l}\text { Sub-second } \\
\text { latency is } \\
\text { critical in } \\
\text { some cases }\end{array}$ & $50 / 60$ \\
\hline & $\begin{array}{l}\text { Transient detection and } \\
\text { analysis }\end{array}$ & & \multirow[t]{2}{*}{500} & \multirow[t]{2}{*}{$25 / 30$} \\
\hline & Voltage stability analysis & & & \\
\hline & $\begin{array}{c}\text { Disturbance } \\
\text { analysis/postmortem } \\
\text { analysis }\end{array}$ & \multirow[t]{2}{*}{31.81} & \multirow[t]{2}{*}{1000} & $50 / 60$ \\
\hline & Frequency response analysis & & & 5 \\
\hline \multirow{3}{*}{$\begin{array}{c}\text { DG } \\
\text { characterization }\end{array}$} & $\begin{array}{l}\text { Feeder voltage coordination } \\
\text { based on DG behavior }\end{array}$ & \multirow[t]{3}{*}{15.915} & \multirow{3}{*}{$\begin{array}{l}\text { No particular } \\
\text { need for } \\
\text { latency }\end{array}$} & \multirow[t]{3}{*}{$50 / 60$} \\
\hline & $\begin{array}{l}\text { Reverse power flow } \\
\text { detection }\end{array}$ & & & \\
\hline & $\begin{array}{l}\text { Disaggregate net metered } \\
\text { DG from load }\end{array}$ & & & \\
\hline \multicolumn{2}{|c|}{ State estimation (SE) } & 0.3181 & 100 & 5 \\
\hline
\end{tabular}

\subsection{Power System Operation (Class D)}

Monitoring and visualization applications are in this class. Some of these applications with their requirements are listed in Table 6. Generally, this group of PMU applications requires a $\leq 1000 \mathrm{~ms}$ latency with medium availability. The message rate requirement for power system monitoring is very low (1-5 samples/cycle [31]).

Table 6. Expected data requirements for power system operation.

\begin{tabular}{|c|c|c|c|c|}
\hline \multicolumn{2}{|c|}{ Application } & Accuracy $(\mu s)$ & Latency $(m s)$ & Message Rate (rep/sec) \\
\hline \multirow{2}{*}{$\begin{array}{l}\text { Topology and } \\
\text { disturbance detection }\end{array}$} & Using time-series signatures & \multirow{2}{*}{15.915} & \multirow{2}{*}{1000} & \multirow{2}{*}{50} \\
\hline & Using source impedance & & & \\
\hline \multirow{3}{*}{ Monitoring } & $\begin{array}{l}\text { Real-time monitoring with } \\
\text { reliability standards }\end{array}$ & \multirow{3}{*}{15.915} & \multirow{3}{*}{1000} & 5 \\
\hline & Real-time monitoring & & & 1 \\
\hline & $\begin{array}{l}\text { Thermal monitoring } \\
\text { (overload) }\end{array}$ & & & 1 \\
\hline \multicolumn{2}{|c|}{ Outage management } & 31.81 & 1000 & $1 \mathrm{sec}$ adequate \\
\hline \multicolumn{2}{|c|}{ Phase $(A B C)$ identification } & 55.56 & $\begin{array}{c}\text { no particular } \\
\text { need for } \\
\text { latency }\end{array}$ & - \\
\hline
\end{tabular}




\subsubsection{Topology and Disturbance Detection}

While voltage and frequency disturbance monitoring is very important for system stability, transient monitoring after switching helps with topology detection. Topology detection is used to define the status of switches (open/closed) in any power system location. Synchronized voltage or current phasors are useful for network topology and disturbance detection. Similar to other monitoring applications, M-class PMUs with high data accuracy and a longer calculation delay are required. Topology and disturbance can be detected based on the time-series signature or based on the source impedance [101]. In both methods, a 0.5\% TVE is adequate if stable [102]. The message rate should be 50 reports per second for a $50 \mathrm{~Hz}$ power system, and the expected processing time requirement is $100 \mathrm{~ms}$ [102]. Some of the topology and disturbance detection methods using PMUs are explained in [104-107].

\subsubsection{Phase Identification}

In a distribution system, many loads are connected to different phases, and this causes current imbalances. Besides that, increasing RESs and dynamic loads such as EVs has a great impact on phase current imbalance. However, there is limited or unreliable information, which hinders the recognition of the phase of connected loads. Furthermore, phase changes are due to the frequent restoration, reconfiguration, and maintenance in the distribution system, and these problems are not always tracked continuously [108]. Incorrect phase labeling is a main source of error in diagnostic processes such as topology detection, state estimation [109], and fault location [110]. Imbalanced currents cause imbalanced voltages, which, due to a sensitivity to this result, can lead to power loss, power failure, or equipment lifespan reduction. Equipment, which is based on inverter technology, three-phase motors, and protection equipment such as relays, reclosers, and circuit breakers, is affected by voltage imbalance [73]. Therefore, correct phase identification is essential to avoid disproportionate concentrations of loads, which lead to phase imbalance. PMUs measure the voltage phase angle directly, which provides an instant visibility of phases. Therefore, a phase can be identified based on time-synchronized voltage phase angle measurements, and it is not sensitive to absolute accuracy or specific time delay (Table 6).

\section{PMU Deployment}

The first PMU prototype was introduced in the early 1980s by the Power System Research Laboratory at Virginia Tech. In 1991, the first commercial PMU was developed by Macrodyne, which was called 1690. Afterwards, many manufacturers started to work on synchrophasor technology. The main manufacturers and companies that develop PMUs are mentioned in Table 7. Alongside PMUs, they also develop many IEDs that work based on synchrophasor technologies. An IED is a microprocessor-based controller for power system equipment, such as circuit breakers, transformers, and capacitor banks [111]. IEDs use data from sensors and actuators for the protection and control of power equipment (Figure 7). However, a new generation of IEDs works with synchrophasor technology. Some synchrophasor-based IEDs, with their applications in distribution systems, are presented in Table 7. As can be seen in the table, they are based on the various PMU applications mentioned in Section 3. It seems that using PMUs and IEDs in distribution systems will increase in the future and will play a significant role in the monitoring, protection, and control of distribution systems and smart grids. 
Table 7. Commercial synchrophasor-based intelligent electronic devices (IEDs).

\begin{tabular}{|c|c|c|}
\hline Company & IED & Application \\
\hline \multirow{3}{*}{$\mathrm{ABB}$} & $\begin{array}{l}\text { PVI-PMU (power } \\
\text { management unit) }\end{array}$ & $\begin{array}{l}\text { Photovoltaic system monitoring, active and reactive } \\
\text { power control [111] }\end{array}$ \\
\hline & $\begin{array}{l}\text { RES670 } 2.0 \text { (relion } 670 \& \\
650 \text { series) }\end{array}$ & Power system protection and control [112] \\
\hline & PSGuard & $\begin{array}{c}\text { SCADA/EMS integration and communication, power } \\
\text { system monitoring including power oscillation, } \\
\text { voltage stability, and line thermal monitoring and } \\
\text { data archiving [113] }\end{array}$ \\
\hline $\begin{array}{l}\text { General Electric, grid } \\
\text { solutions }\end{array}$ & MiCOM P40 Agile & Feeder management [114] \\
\hline EATON & $\begin{array}{l}\text { GearGard (condition } \\
\text { remote monitoring and } \\
\text { early failure warning } \\
\text { solutions) }\end{array}$ & $\begin{array}{c}\text { Real-time monitoring, statistical analysis, and } \\
\text { condition-based maintenance decisions are becoming } \\
\text { the basis for the remote supervision of electrical } \\
\text { equipment and systems [115] }\end{array}$ \\
\hline Mehta Tec & $\begin{array}{l}\text { Data fault recorder } \\
\text { (DFR)/disturbance } \\
\text { monitoring equipment } \\
(\mathrm{DME}) / \mathrm{PMU}\end{array}$ & $\begin{array}{l}\text { Online disturbance monitoring and data } \\
\text { archiving [116] }\end{array}$ \\
\hline \multirow{3}{*}{ Macrodyne } & 1690 & $\begin{array}{l}\text { Phasor measurement systems for real-time data } \\
\text { acquisition and control [117] }\end{array}$ \\
\hline & 1692 & $\begin{array}{c}\text { Integrated recording units for transient fault and } \\
\text { long-term disturbance events [118] }\end{array}$ \\
\hline & $1698,1698 \mathrm{E}$ & $\begin{array}{l}\text { Satellite timing units for absolute time tagging and } \\
\text { synchronous data sampling }[119,120]\end{array}$ \\
\hline \multirow{3}{*}{$\begin{array}{l}\text { Schweitzer Engineering } \\
\text { Laboratories (SEL) }\end{array}$} & SEL-2411 & Programmable automation controller [120] \\
\hline & SEL-T400L & $\begin{array}{c}\text { Line protection with simple configuration, accurate } \\
\text { fault locating, and high-resolution } \\
\text { oscillography [121] }\end{array}$ \\
\hline & SEL-411L & $\begin{array}{l}\text { Line current differential, distance, and directional } \\
\text { overcurrent protection, comprehensive monitoring, } \\
\text { advanced automation and communication, } \\
\text { high-accuracy fault locating [122] }\end{array}$ \\
\hline S\&C electric company & 6800 series & $\begin{array}{l}\text { Control and manage distribution switches } \\
\text { automatically [123] }\end{array}$ \\
\hline $\begin{array}{l}\text { Power Standards } \\
\quad \text { Lab (PSL) }\end{array}$ & PQube ( $\mu$ PMU) & $\begin{array}{l}\text { Cyber-attacks detection, power consumption } \\
\text { analysis, remotely understand commercial AC power } \\
\text { grids, provide input for solar PV and storage control } \\
\text { system development, simulation and data } \\
\text { integration for solar planning tools, short-term } \\
\text { planning and operations, to understand geomagnetic } \\
\text { disturbance effects on distribution grids and } \\
\text { industrial equipment [124] }\end{array}$ \\
\hline Siemens & $\begin{array}{l}\text { SIGUARD PDP (phasor } \\
\text { data processor) }\end{array}$ & $\begin{array}{l}\text { Complete portfolio for network monitoring, power } \\
\text { quality recording, fault recording, phasor } \\
\text { measurement, and system software applications [28] }\end{array}$ \\
\hline
\end{tabular}

\section{Conclusions}

Besides the advantages of using PMUs in power systems, PMU applications are faced with many challenges in distribution systems, such as inadequate phasor measurement accuracy and a lack of communication network infrastructure that can support a large number of sensors and actuators 
with different technologies. Therefore, using a single comprehensive data/sensor architecture is an opportunity for distribution systems to access high-accuracy voltage and current phasors using PMUs. As described in the paper, the protection and control applications of PMUs require more accurate and very fast communication technologies. It seems that by developing new communication technologies such as $5 \mathrm{G}$, this problem will be solved in the near future. However, the installation of a large number of PMUs in a distribution system will be costly for distribution system operators. Fortunately, by using an efficient optimization method, the number of PMUs needed for a given system will decrease. In addition, the price of this device will likely be reduced if the use of this technology is increased and the PMU size is reduced. Thus, power systems without SCADA/EMS systems, with monitoring systems at each voltage level, and with fast protection and control action at super PDCs or even PDCs may be within reach.

Author Contributions: U.D. initiated and coordinated the work and also reviewed the article. M.H. collected the data, investigated on PMU applications in power systems, and finally wrote the paper. A.P. and P.B. reviewed the article and gave valuables guidance on power systems.

Funding: This research received no external funding.

Conflicts of Interest: The authors declare no conflict of interest.

\section{Abbreviations}

$\begin{array}{ll}\text { AMI } & \text { Automated Metering Infrastructure } \\ \text { BB } & \text { Broadband } \\ \text { CAPEX } & \text { Capital Expenses } \\ \text { UTC } & \text { Coordinated Universal Time } \\ \text { CT } & \text { Current Transformer } \\ \text { DER } & \text { Distributed Energy Resources } \\ \text { DFR } & \text { Data Fault Recorder } \\ \text { DG } & \text { Distributed Generator } \\ \text { D-FACTS } & \text { Distributed FACTS } \\ \text { DME } & \text { Disturbance Monitoring Equipment } \\ \text { DSE } & \text { Dynamic SE } \\ \text { EMS } & \text { Energy Management System } \\ \text { eMBB } & \text { Enhanced Mobile Broadband } \\ \text { EVs } & \text { Electric Vehicles } \\ \text { FACTS } & \text { Flexible AC Transmission System } \\ \text { FL } & \text { Fault Location } \\ \text { GPS } & \text { Global Positioning System } \\ \text { GMA } & \text { Grid Monitoring and Automation } \\ \text { HVDC } & \text { High-voltage Direct Current } \\ \text { IoT } & \text { Internet of Things } \\ \text { LCOE } & \text { Levelized Cost of Electricity } \\ \text { IED } & \text { Intelligent Electronic Device } \\ \text { LFC } & \text { Load Frequency Control } \\ \text { LTE } & \text { Long-Term Evolution } \\ \text { LV } & \text { Low Voltage } \\ \text { MMG } & \text { Maritime Microgrid } \\ \text { mMTC } & \text { Machine-Type Communications } \\ \text { MTC } & \text { Mission- and Time-Critical } \\ \text { MV } & \text { Medium Voltage } \\ \text { NB } & \text { Narrowband } \\ \text { NAPSI } & \text { North American Synchrophasor Initiative } \\ \text { OPEX } & \text { Operational Expenses } \\ & \end{array}$




$\begin{array}{ll}\text { PDC } & \text { Phasor Data Concentrator } \\ \text { PMU } & \text { Phasor Measurement Unit } \\ \text { PT } & \text { Potential Transformer } \\ \text { PLC } & \text { Power Line Communication } \\ \text { PLUS } & \text { Power Line data bUS } \\ \text { PSL } & \text { Power Standards Lab } \\ \text { PS } & \text { Primary Substation } \\ \text { QoS } & \text { Quality of Service } \\ \text { OPP } & \text { Optimal PMU Placement } \\ \text { ROCOF } & \text { Rate of Change of Frequency } \\ \text { RTU } & \text { Remote Terminal Unit } \\ \text { RER } & \text { Renewable Energy Resources } \\ \text { SEL } & \text { Schweitzer Engineering Laboratories } \\ \text { SE } & \text { State Estimation } \\ \text { SSE } & \text { Static SE } \\ \text { SCADA } & \text { Supervisory Control and Data Acquisition } \\ \text { TVE } & \text { Total Vector Error } \\ \text { URLLC } & \text { Ultra-Reliability Low-Latency Communications } \\ \text { WAMS } & \text { Wide-Area Monitoring System }\end{array}$

\section{References}

1. Oettinger, G.H. Energy Roadmap 2050; Publications Office of the European Union: Brussels, Belgium, 2011. [CrossRef]

2. Jordehi, A.R. How to Deal with Uncertainties in Electric Power Systems? A Review. Renew. Sustain. Energy Rev. 2018, 96, 145-155. [CrossRef]

3. Hirth, L. The Market Value of Variable Renewables. The Effect of Solar Wind Power Variability on Their Relative Price. Energy Econ. 2013, 38, 218-236. [CrossRef]

4. Edenhofer, O.; Hirth, L.; Knopf, B.; Pahle, M.; Schlömer, S.; Schmid, E.; Ueckerdt, F. On the Economics of Renewable Energy Sources. Energy Econ. 2013, 40, 12-23. [CrossRef]

5. Ueckerdt, F.; Hirth, L.; Luderer, G.; Edenhofer, O. System LCOE: What Are the Costs of Variable Renewables? Energy 2013, 63, 61-75. [CrossRef]

6. Akrami, A.; Doostizadeh, M.; Aminifar, F. Power System Flexibility: An Overview of Emergence to Evolution. J. Mod. Power Syst. Clean Energy 2019, 7, 987-1007. [CrossRef]

7. Negnevitsky, M. High Renewable Energy Penetration and Power System Security: New Challenges and Opportunities. In Proceedings of the 10th International Scientific Symposium on Electrical Power Engineering ELEKTROENERGETIKA, Stará Lesná, Slovakia, 16-18 September 2019; pp. 16-25.

8. Colmenar-Santos, A.; Campíñez-Romero, S.; Pérez-Molina, C.; Castro-Gil, M. Profitability Analysis of Grid-Connected Photovoltaic Facilities for Household Electricity Self-Sufficiency. Energy Policy 2012, 51, 749-764. [CrossRef]

9. Lai, C.S.; McCulloch, M.D. Levelized Cost of Electricity for Solar Photovoltaic and Electrical Energy Storage. Appl. Energy 2017, 190, 191-203. [CrossRef]

10. Gómez, A.; Dopazo, C.; Fueyo, N. The "Cost of Not Doing” Energy Planning: The Spanish Energy Bubble. Energy 2016, 101, 434-446. [CrossRef]

11. Byrne, R.H.; Trudnowski, D.J.; Neely, J.C.; Elliott, R.T.; Schoenwald, D.A.; Donnelly, M.K. Optimal Locations for Energy Storage Damping Systems in the Western North American Interconnect. In Proceedings of the IEEE PES General Meeting Conference \& Exposition, National Harbor, MD, USA, 27-31 July 2014; pp. 1-5. [CrossRef]

12. Power System Engineering, Inc. Available online: https://www.powersystem.org/scada (accessed on 28 November 2019).

13. Liu, Y.; You, S.; Yao, W.; Cui, Y.; Wu, L.; Zhou, D.; Zhao, J.; Liu, H.; Liu, Y. A Distribution Level Wide Area Monitoring System for the Electric Power Grid-FNET/GridEye. IEEE Access 2017, 5, 2329-2338. [CrossRef]

14. Aminifar, F.; Khodaei, A.; Fotuhi-Firuzabad, M.; Shahidehpour, M. Contingency-Constrained PMU Placement in Power Networks. IEEE Trans. Power Syst. 2010, 25, 516-523. [CrossRef] 
15. Akhlaghi, S. Optimal PMU Placement Considering Contingency-Constraints for Power System Observability and Measurement Redundancy. In Proceedings of the 2016 IEEE Power and Energy Conference at Illinois (PECI), Urbana, IL, USA, 19-20 February 2016; pp. 1-7. [CrossRef]

16. Akhlaghi, S.; Zhou, N.; Wu, N.E. PMU Placement for State Estimation Considering Measurement Redundancy and Controlled Islanding. In Proceedings of the 2016 IEEE Power and Energy Society General Meeting (PESGM), Boston, MA, USA, 17-21 July 2016; pp. 1-5. [CrossRef]

17. Xie, N.; Torelli, F.; Bompard, E.; Vaccaro, A. A Graph Theory Based Methodology for Optimal PMUs Placement and Multiarea Power System State Estimation. Electr. Power Syst. Res. 2015, 119, 25-33. [CrossRef]

18. Sarailoo, M.; Wu, N.E. A New PMU Placement Algorithm to Meet a Specified Synchrophasor Availability. In Proceedings of the 2016 IEEE Power \& Energy Society Innovative Smart Grid Technologies Conference (ISGT), Minneapolis, MN, USA, 6-9 September 2016; pp. 1-5. [CrossRef]

19. Li, Q.; Cui, T.; Weng, Y.; Negi, R.; Franchetti, F.; Ilic, M.D. An Information-Theoretic Approach to PMU Placement in Electric Power Systems. IEEE Trans. Smart Grid 2013, 4, 446-456. [CrossRef]

20. Zhang, C.; Jia, Y.; Xu, Z.; Lai, L.L.; Wong, K.P. Optimal PMU Placement Considering State Estimation Uncertainty and Voltage Controllability. IET Gener. Transm. Distrib. 2017, 11, 4465-4475. [CrossRef]

21. Miron, S. From SCADA to smart grid in power transmission and distribution systems. Bul. AGIR 2011, 4, 191-198.

22. IEEE Standard for Synchrophasor Measurements for Power Systems; IEEE: Piscataway, NJ, USA, 2011.

23. IEEE Standard for Synchrophasor Measurements for Power Systems-Amendment 1: Modification of Selected Performance Requirements; IEEE Std. C37.118.1a-2014 (Amendment to IEEE Std C37.118.1-2011); IEEE: Piscataway, NJ, USA, 2014; pp. 1-25. [CrossRef]

24. Simens. Phasor Measurement Unit (PMU) and Grid Monitoring. Available online: https://w3.siemens.com/smartgrid/global/en/products-systems-solutions/protection/pmu-phasormeasurment-unit/pages/pmu-phasor-measurement-unit.aspx (accessed on 28 November 2019).

25. Singh, B.; Sharma, N.; Tiwari, A.; Verma, K.; Singh, S. Applications of phasor measurement units (PMUs) in electric power system networks incorporated with FACTS controllers. Int. J. Eng. Sci. Technol. 2011, 3, 64-82. [CrossRef]

26. Galleon Sysmtems. Available online: https://www.atomic-clock.galleon.eu.com/support/gps-time-accuracy.html (accessed on 28 November 2019).

27. Mina, T.Y.; Bhamidipati, S.; Gao, G.X. Detecting GPS spoofing via a multi-receiver hybrid communication network for power grid timing verification. In Proceedings of the 31st International Technical Meeting of the Satellite Division of The Institute of Navigation (ION GNSS+ 2018), Hyatt Regency Miami, FL, USA, 24-28 September 2018; pp. 2963-2977. [CrossRef]

28. Mini, S.T.; McDonald, J.D. Power System SCADA and Smart Grids, 1st ed.; CRC Press: Boca Raton, FL, USA, 2015.

29. Sundararajan, A.; Khan, T.; Moghadasi, A.; Sarwat, A.I. A survey on synchrophasor data quality and cybersecurity challenges, and evaluation of their interdependencies. J. Mod. Power Syst. Clean Energy 2018, 7, 1-18. [CrossRef]

30. Lira, R.; Mycock, C.; Wilson, D.; Kang, H. PMU Performance Requirements and Validation for Closed Loop Applications. In Proceedings of the 2011 2nd IEEE PES International Conference and Exhibition on Innovative Smart Grid Technologies, Manchester, UK, 5-7 December 2011; pp. 1-7. [CrossRef]

31. Miller, L.E.; Silverstein, A.; Anand, D.; Goldstein, A.; Makarov, Y.; Tuffner, F.; Jones, K. PMU Data Quality: A Framework for the Attributes of PMU Data Quality and a Methodology for Examining Data Quality Impacts to Synchrophasor Applications; NASPI: Washington, DC, USA, 2017; pp. 1-77.

32. Chakrabortty, A.; Ilić, M.D. Control and Optimization Methods for Electric Smart Grids, 1st ed.; Ilic, M.D., Ed.; Springer: Berlin, Germany, 2012. [CrossRef]

33. Huang, C.; Li, F.; Zhou, D.; Guo, J.; Pan, Z.; Liu, Y.; Liu, Y. Data quality issues for Synchrophasor applications Part I: A review. J. Mod. Power Syst. Clean Energy 2016, 4, 342-352. [CrossRef]

34. Arghira, N.; Hossu, D.; Făgărăşan, I.; Iliescu, S.S.; Costianu, D.R. Modern scada philosophy in power system operation-A survey. UPB Sci. Bull. Ser. C Electr. Eng. 2011, 73, 153-166.

35. Siow, L.K.; So, P.L.; Gooi, H.B.; Luo, F.L.; Gajanayake, C.J.; Vo, Q.N. Wi-Fi Based Server in Microgrid Energy Management System. In Proceedings of the TENCON 2009-2009 IEEE Region 10 Conference, Singapore, 23-26 January 2009; pp. 1-5. [CrossRef] 
36. Eissa, M.M. New Protection Principle for Smart Grid with Renewable Energy Sources Integration Using WiMAX Centralized Scheduling Technology. Int. J. Electr. Power Energy Syst 2018, 97, 372-384. [CrossRef]

37. Batista, N.C.; Melício, R.; Matias, J.C.O.; Catalão, J.P.S. Photovoltaic and Wind Energy Systems Monitoring and Building/Home Energy Management Using ZigBee Devices within a Smart Grid. Energy 2013, 49, 306-315. [CrossRef]

38. Castello, P.; Ferrari, P.; Flammini, A.; Muscas, C.; Pegoraro, P.A.; Rinaldi, S. A distributed PMU for electrical substations with wireless redundant process bus. IEEE Trans. Instrum. Meas. 2015, 64, 1149-1157. [CrossRef]

39. Ali, J.; Ahmed, U.; Farhan, M. Framework for Implementation of AGA 12 for Secured SCADA Operation in Oil and Gas Industry. In Proceedings of the 2015 2nd International Conference on Computing for Sustainable Global Development (INDIACom), New Delhi, India, 11-13 March 2015. [CrossRef]

40. Chenine, M.; Nordstrom, L. Modeling and simulation of wide-area communication for centralized PMU-based applications. IEEE Trans. Power Deliv. 2011, 26, 1372-1380. [CrossRef]

41. Chin, W.L.; Li, W.; Chen, H.H. Energy big data security threats in IoT-based smart grid communications. IEEE Commun. Mag. 2017, 55, 70-75. [CrossRef]

42. Katsaros, K.V.; Yang, B.; Chai, W.K.; Pavlou, G. Low Latency Communication Infrastructure for Synchrophasor Applications in Distribution Networks. In Proceedings of the IEEE International Conference on Smart Grid Communication, Venice, Italy, 3-6 November 2014. [CrossRef]

43. Kumar, S.; Soni, S.K.; Jain, D.K. Requirements and challenges of PMUs communication in WAMS environment requirements and challenges of PMUS communication in WAMS enviroment. Far East J. Electron. Commun. 2014, 13, 121-135.

44. Unsal, D.B.; Yalcinoz, T. Applications of new power line communication model for smart grids. Int. J. Comput. Electr. Eng. 2015, 7, 168-178. [CrossRef]

45. Dostert, K. Powerline Communications; Prentice Hall: Upper Saddle River, NJ, USA, 2001.

46. Lampe, L.; Andrea, T.T.; Swart, G. (Eds.) Power Line Communications: Principles, Standards and Applications from Multimedia to Smart Grid, 2nd ed.; John Wiley \& Sons: Hoboken, NJ, USA, 2016. [CrossRef]

47. Dominiak, S.; Dersch, U. Precise Time Synchronization of Phasor Measurement Units with Broadband Power Line Communications; Swiss Federal Office of Energy SFOE: Bern, Switaerland, 2017.

48. Benato, R.; Caldon, R. Application of PLC for the control and the protection of future distribution networks. In Proceedings of the IEEE International Symposium on Power Line Communications and Its Applications, Pisa, Italy, 26-28 March 2007; pp. 499-504. [CrossRef]

49. Dersch, U. PLUS (Power Line Data BUS ) Based Avionics Data Bus Power PLUS Data over the Same Aircraft Wiring-Reducing Its Weight, Volume and Complexity P Ower L Ine Data B US PLUS Protocol E Technology Platform; PLUS: Amstelveen, The Netherlands, 2016.

50. Thomas Heuzeroth. Die Ganze Wahrheit Über die Nächste Mobilfunk-Generation. Available online: https://www.welt.de/wirtschaft/webwelt/article189459047/5G-Die-ganze-Wahrheit-ueber-dienaechste-Mobilfunk-Generation.html (accessed on 28 November 2019).

51. Popovski, P.; Trillingsgaard, K.; Osvaldo, S.; Durisi, G. 5G Wireless Network Slicing for EMBB, URLLC, and MMTC: A Communication-Theoretic View. IEEE Access 2018, 6, 55765-55779. [CrossRef]

52. Cosovic, M.; Tsitsimelis, A.; Vukobratovic, D.; Matamoros, J.; Anton-Haro, C. 5G Mobile Cellular Networks: Enabling Distributed State Estimation for Smart Grids. IEEE Commun. Mag. 2017, 55, 62-69. [CrossRef]

53. Rana, M.; Li, L.; Su, S. Kalman Filter Based Microgrid State Estimation and Control Using the IoT with 5G Networks. In Proceedings of the IEEE PES Asia-Pacific Power and Energy Engineering Conference (APPEEC), Brisbane, QLD, Australia, 15-18 November 2015. [CrossRef]

54. Gheisarnejad, M.; Khooban, M.-H.; Dragicevic, T. The Future 5G Network Based Secondary Load Frequency Control in Maritime Microgrids. IEEE J. Emerg. Sel. Top. Power Electron. 2019, 1-8. [CrossRef]

55. DotEcon Ltd. Axon Partners. In Study on Implications of 5G Deployment on Future Business Models Axon Partners Group; DotEcon Ltd.: Lundon, UK, 2018.

56. 5G Americas White Paper. 5G The Future of IoT. Available online: https://www.5gamericas:5g-the-future-of-iot/ (accessed on 28 November 2019).

57. Smart Grids Infrastructure, Technology, and Solutions, 1st ed.; Stuart, B. (Ed.) Taylor \& Francis: Lundon, UK, 2013. [CrossRef] 
58. Martínez, C.; Parashar, M.; Dyer, J.; y Coroas, J. Real time monitoring, control and protection. Phasor data requirements for real time wide-area monitoring, control and protection applications. Consort. Electr. Reliab. Technol. Solut. 2005, 26, 8 .

59. KTH(SE). Distribution Network Dynamics Monitoring, Control, and Protection Solutions Including Their Interface to TSOs; KTH Royal Institute of Technology: Stockholm, Sweden, 2015.

60. Kong, X.; Chen, Y.; Xu, T.; Wang, C.; Yong, C.; Li, P.; Yu, L. A hybrid state estimator based on SCADA and PMU measurements for medium voltage distribution system. Appl. Sci. 2018, 8, 1527. [CrossRef]

61. Kansal, P.; Bose, A. Bandwidth and latency requirements for smart transmission grid applications. IEEE Trans. Smart Grid 2012, 3, 1344-1352. [CrossRef]

62. Von Meier, A.; Culler, D.; McEachern, A.; Arghandeh, R. Micro-Synchrophasors for distribution systems. In Proceedings of the IEEE PES Innovative Smart Grid Technologies Conference (ISGT), Washington, DC, USA, 19-22 February 2014; pp. 1-5. [CrossRef]

63. Bag, G.; Thrybom, L.; Hovila, P. Challenges and Opportunities of 5G in Power Grids. CIRED Open Access Proc. J. 2017, 2017, 2145-2148. [CrossRef]

64. Almas, M.S.; Vanfretti, L. RT-HIL Implementation of the hybrid Synchrophasor and GOOSE-based passive islanding schemes. IEEE Trans. Power Deliv. 2016, 31, 1299-1309. [CrossRef]

65. Usman, M.U.; Faruque, M.O. Applications of synchrophasor technologies in power systems. J. Mod. Power Syst. Clean Energy 2019, 7, 211-226. [CrossRef]

66. IEEE Std 1547-2018 Bulk System Opportunities from New Distributed Energy Resource Interconnection and Standards Disclaimer and Acknowledgment; IEEE: Piscataway, NJ, USA, 2019.

67. Appasani, B.; Mohanta, D.K. A review on Synchrophasor communication system: Communication technologies, standards and applications. Prot. Control Mod. Power Syst. 2018, 3, 37. [CrossRef]

68. Borghetti, A.; Nucci, C.A.; Paolone, M.; Ciappi, G.; Solari, A. Synchronized phasors monitoring during the islanding maneuver of an active distribution network. IEEE Trans. Smart Grid 2011, 2, 70-79. [CrossRef]

69. Sun, R.; Centeno, V.A. Wide area system islanding contingency detecting and warning scheme. IEEE Trans. Power Syst. 2014, 29, 2581-2589. [CrossRef]

70. Franco, R.; Sena, C.; Taranto, G.N.; Giusto, A. Using Synchrophasors for controlled islanding-A prospective application for the uruguayan power system. IEEE Trans. Power Syst. 2013, 28, 2016-2024. [CrossRef]

71. Von Meier, A.; Berkeley, U.C.; Brady, K.; Berkeley, U.C.; Brown, M.; Berkeley, U.C.; Cotter, G.R.; Llc, I. Synchrophasor Monitoring for Distribution Systems: Technical Foundations and Applications A White Paper by the NASPI Distribution Task Team; NASPI: Berkeley, CA, USA, 2018.

72. Zhou, Y.; Arghandeh, R.; Konstantakopoulos, I.; Abdullah, S.; Von Meier, A.; Spanos, C.J. Abnormal event detection with high resolution micro-PMU data. In Proceedings of the 19th Power Systems Computation Conference (PSCC), Genoa, Italy, 20-24 June 2016; pp. 1-7. [CrossRef]

73. Kumar, S.; Soni, M.K.; Jain, D.K. Monitoring of wide area power system network with phasor data concentrator (PDC). Int. J. Inf. Eng. Electron. Bus. 2015, 7, 20-26. [CrossRef]

74. Dahal, O.P.; Cao, H.; Brahma, S.; Kavasseri, R. Evaluating performance of classifiers for supervisory protection using disturbance data from phasor measurement units. In Proceedings of the IEEE PES Innovative Smart Grid Technologies, Istanbul, Turkey, 12-15 October 2015; pp. 1-6. [CrossRef]

75. Biswal, M.; Brahma, S.M.; Cao, H. Supervisory protection and automated event diagnosis using PMU data. IEEE Trans. Power Deliv. 2016, 31, 1855-1863. [CrossRef]

76. Ree, J.D.L.; Centeno, V.; Thorp, J.S.; Phadke, A.G. Synchronized phasor measurement applications in power systems. IEEE Trans. Smart Grid 2010, 1, 20-27.

77. Dobakhshari, A.S.; Ranjbar, A.M. A novel method for fault location of transmission lines by wide-area voltage measurements considering measurement errors. IEEE Trans. Smart Grid 2015, 6, 874-884. [CrossRef]

78. Wu, T.; Li, J.; Kamwa, I.; Chung, C.-Y.; Qin, M. Synchrophasor measurement-based fault location technique for multi-terminal multi-section non-homogeneous transmission lines. IET Gener. Transm. Distrib. 2016, 10, 1815-1824. [CrossRef]

79. Jamali, S.; Bahmanyar, A. A new fault location method for distribution networks using sparse measurements. Int. J. Electr. Power Energy Syst. 2016, 81, 459-468. [CrossRef]

80. Orozco-Henao, C.; Bretas, A.S.; Chouhy-Leborgne, R.; Herrera-Orozco, A.R.; Marín-Quintero, J. Active distribution network fault location methodology: A minimum fault reactance and fibonacci search approach. Int. J. Electr. Power Energy Syst. 2017, 84, 232-241. [CrossRef] 
81. Madhusudan, R.; Ramamohan Rao, G. Modeling and Simulation of a Distribution STATCOM (D-STATCOM) for Power Quality Problems-Voltage Sag and Swell Based on Sinusoidal Pulse Width Modulation (SPWM). In Proceedings of the IEEE International Conference on Advances in Engineering, Science and Management, Nagapattinam, Tamil Nadu, India, 30-31 March 2012; pp. 436-441.

82. Radhakrishna, K.R.; Ananthapadmanabha, D.T.; Kumar, M.V.L.; Chidanandappa, R. Minimization of losses in distribution system with D-Facts devices. Int. J. Electr. Eng. Technol. 2016, 7, 1-15.

83. Zafari, A.; Jazaeri, M. STATCOM Systems in Distribution and Transmission System Applications: A Review of Power-Stage Topologies and Control Methods. Int. Trans. Electr. Energy Syst 2016, 26, 323-346. [CrossRef]

84. Shahsavari, A.; Farajollahi, M.; Stewart, E.; Cortez, E.; Mohsenian-Rad, H. Situational awareness in distribution grid using micro-PMU data: A machine learning approach. IEEE Trans. Smart Grid 2019, 10, 6167-6177. [CrossRef]

85. Wischkaemper, J.A.; Benner, C.L.; Russell, B.D.; Manivannan, K. Application of waveform analytics for improved situational awareness of electric distribution feeders. IEEE Trans. Smart Grid 2015, 6, 2041-2049. [CrossRef]

86. Wu, J.; Ota, K.; Dong, M.; Li, J.; Wang, H. Big data analysis-based security situational awareness for smart grid. IEEE Trans. Big Data 2016, 4, 408-417. [CrossRef]

87. Chen Sun, C.S.; Dong Liu, D.L.; Yun Wang, Y.W. Operation Situational Awareness Based on Dynamic Power Flow for a Profound Analysis of Active Distribution Network. In Proceedings of the CIRED Workshop, Helsinki, Finland, 14-15 June 2016. [CrossRef]

88. Vanfretti, L.; Chow, J.H.; Sarawgi, S.; Fardanesh, B. A phasor-data-based state estimator incorporating phase bias correction. IEEE Trans. Power Syst. 2011, 26, 111-119. [CrossRef]

89. Jovicic, A.; Jereminov, M.; Pileggi, L.; Hug, G. A Linear Formulation for Power System State Estimation Including RTU and PMU Measurements. arXiv 2018, arXiv:1812.00070.

90. Abur, A. Phasor-Only State Estimation Ali. PSERC Webinar. Boston October 2014.

91. Aminifar, F.; Shahidehpour, M.; Fotuhi-Firuzabad, M.; Kamalinia, S. Power system dynamic state estimation with synchronized phasor measurements. IEEE Trans. Instrum. Meas. 2014, 63, 352-363. [CrossRef]

92. Do Coutto Filho, M.B.; Stacchini de Souza, J.C. Forecasting-aided state estimation-Part I: Panorama. IEEE Trans. Power Syst. 2009, 24, 1667-1677. [CrossRef]

93. Do Coutto Filho, M.B.; Stacchini de Souza, J.C.; Freund, R.S. Forecasting-aided state estimation-part II: Implementation. IEEE Trans. Power Syst. 2009, 24, 1678-1685. [CrossRef]

94. Gol, M.; Abur, A. A Robust PMU based three-phase state estimator using modal decoupling. IEEE Trans. Power Syst. 2014, 29, 2292-2299. [CrossRef]

95. Alok, J.; Suman, B. Micro-Phasor Measurement Units (MPMUs) and Its Applications in Smart Distribution Systems; Springer: Singapore, 2017. [CrossRef]

96. Pulok, M.K.H.; Faruque, M.O. Utilization of PMU data to evaluate the effectiveness of voltage stability boundary and indices. In Proceedings of the North American Power Symposium (NAPS), Charlotte, NC, USA, 4-6 October 2015; pp. 1-6. [CrossRef]

97. Rodrigues, A.B.; Prada, R.B.; Da Silva, M.D.G. Voltage stability probabilistic assessment in composite systems: Modeling unsolvability and controllability loss. IEEE Trans. Power Syst. 2010, 25, 1575-1588. [CrossRef]

98. Liu,J.H.; Chu, C.C. Wide-area measurement-based voltage stability indicators by modified coupled single-port models. IEEE Trans. Power Syst. 2014, 29, 756-764. [CrossRef]

99. Gao, Q.; Rovnyak, S.M. Decision trees using synchronized phasor measurements for wide-area response-based control. IEEE Trans. Power Syst. 2011, 26, 855-861. [CrossRef]

100. Teeuwsen, S.P.; Erlich, I.; El-Sharkawi, M.A.; Bachmann, U. Genetic algorithm and decision tree-based oscillatory stability assessment. IEEE Trans. Power Syst. 2006, 21, 746-753. [CrossRef]

101. Dulău, L.I.; Abrudean, M.; Bică, D. Effects of distributed generation on electric power systems. Procedia Technol. 2014, 12, 681-686. [CrossRef]

102. Stewart, E.; McEachern, A.; Mehrmanesh, L.; von Meier, A.; Andersen, M. Precision micro-synchrophasors for distribution systems: A summary of applications. IEEE Trans. Smart Grid 2017, 8, 2926-2936. [CrossRef]

103. Allen, E.; Kosterev, D.; Pourbeik, P. Validation of power system models. In Proceedings of the IEEE PES General Meeting, Providence, RI, USA, 25-29 July 2010; pp. 1-7. [CrossRef] 
104. Cavraro, G.; Arghandeh, R.; Barchi, G.; Von Meier, A. Distribution Network Topology Detection with Time-Series Measurements. In Proceedings of the IEEE Power \& Energy Society Innovative Smart Grid Technologies Conference (ISGT), Washington, DC, USA, 18-20 February 2015; pp. 1-5. [CrossRef]

105. Cavraro, G.; Arghandeh, R.; Poolla, K.; Von Meier, A. Data-Driven Approach for Distribution Network Topology Detection. In Proceedings of the IEEE Power \& Energy Society General Meeting, Denver, CO, USA, 26-30 July 2015; pp. 1-5. [CrossRef]

106. Talukdar, S.; Deka, D.; Materassi, D.; Salapaka, M. Exact Topology Reconstruction of Radial Dynamical Systems with Applications to Distribution System of the Power Grid. In Proceedings of the American Control Conference, Seattle, DC, USA, 24-26 May 2017.

107. Arghandeh, R.; Cavraro, G.; Renewable, N. Topology Detection in Microgrids With Micro-Synchrophasors. In Proceedings of the IEEE Power \& Energy Society General Meeting, Denver, CO, USA, 26-30 July 2015.

108. Wen, M.H.F.; Arghandeh, R.; Von Meier, A.; Poolla, K.; Li, V.O.K. Phase identification in distribution networks with micro-Synchrophasors. In Proceedings of the IEEE Power \& Energy Society General Meeting, Denver, CO, USA, 26-30 July 2015; pp. 1-5.

109. Schenato, L.; Barchi, G.; Macii, D.; Arghandeh, R.; Poolla, K.; Von Meier, A. Bayesian Linear State Estimation Using Smart Meters and PMUs Measurements in Distribution Grids. In Proceedings of the IEEE International Conference on Smart Grid Communications (SmartGridComm), Venice, Italy, 3-6 November 2014; pp. 572-577. [CrossRef]

110. Von Meier, A.; Arghandeh, R. Every Moment Counts: Synchrophasors for Distribution Networks with Variable Resources. In Renewable Energy Integration; Academic Press: Cambridge, MA, USA, 2017; pp. 435-444. [CrossRef]

111. ABB. Available online: https://new.abb.com/products/6AGC002439?printPreview (accessed on 28 November 2019).

112. ABB North America. Relion Protection and Control. Available online: https://library.e.abb.com/public/ 67fe820fa3324e31c1257c0600350af7/9AKK105713A8738_LoRes_A_en_Relion_protection_and_control_for_ generation_transmission_and_sub-transmission_-_ABB_North.pdf (accessed on 28 november 2019).

113. ABB. Available online: https://new.abb.com/substation-automation/systems/wide-area-monitoring-system (accessed on 28 November 2019).

114. ManualsLib. Available online: https://www.manualslib.com/manual/1316991/Ge-Micom-P40-Agile-P14d.html (accessed on 28 November 2019).

115. EATON. Available online: https:/www.eaton.com/content/dam/eaton/services/eess/eess-documents/ geargard-sa02204002e.pdf (accessed on 28 November 2019).

116. Mehta Tech, Inc. Available online: http://www.mehtatech.com/pdfs/dfr-pmu-poster.pdf (accessed on 28 November 2019).

117. Macrodyne. Available online: Availableonline:https://www.macrodyneusa.com/model_1690.htm (accessed on 28 November 2019).

118. Macrodyne. Available online: https://www.macrodyneusa.com/model_1692.htm (accessed on 28 November 2019).

119. Macrodyne. Available online: https://www.macrodyneusa.com/model_1698.htm (accessed on 28 November 2019).

120. Schweitzer Engineering Labratories. Available online: https://selinc.com/products/2411/ (accessed on 28 November 2019).

121. Schweitzer Engineering Labratories. Available online: https://selinc.com/products/T400L/ (accessed on 28 November 2019).

122. Schweitzer Engineering Labratories. Available online: https://selinc.com/products/411L/ (accessed on 28 November 2019).

123. S\&C Electric Company. Available online: https://www.sandc.com/en/products--services/products/6800series-automatic-switch-control/ (accessed on 28 November 2019). 
124. Power Standards Lab. Available online: https://www.powerstandards.com/news_events/pqube-3-poweranalyzers-unique-design-and-benefits-wins-power-standards-lab-an-ecm-2018-award/ (accessed on 28 November 2019).

(). (1)

(C) 2019 by the authors. Licensee MDPI, Basel, Switzerland. This article is an open access article distributed under the terms and conditions of the Creative Commons Attribution (CC BY) license (http://creativecommons.org/licenses/by/4.0/). 